\title{
Biobutanol: Production, Scope and Challenges
}

\author{
Sonam Antil* \\ College of Basic Sciences and Humanities, CCS HAU, Hisar, Haryana 125004, India \\ *Corresponding author
}

\section{A B S T R A C T}

Keywords

Biobutanol, Fuel, Production process

Article Info

Accepted:

07 October 2019

Available Online:

0 November 2019
The increasing scarcity of traditional fossil fuels along with increasing pollution as a result of their overexploitation has entailed the need for renewable fuels. As a result, fuels derived from biomass are gaining credit due to their economic feasibility and environment-friendly nature. Among available liquid biofuels, biobutanol is being considered as an apt and sustainable substitute of gasoline. Fate and mercantile of butanol production through fermentative route thoroughly depend on the selection of a suitable feedstock. The modern artificial biology provides additional tools to engineer artificial pathways in user-friendly hosts to help increase thresholds and productivity of bio-butanol. This review summarises the production process of biobutanol, its scope and challenges that come across in the way of its commercial use.

\section{Introduction}

Continuous depletion of non- renewable energy sources, petroleum products and increasing prices of raw materials are the main reasons for searching alternative fuels from renewable energy sources and biofuels. Initially, the whole attention has been put on bioethanol because of raw material availability for its production and defined techniques for isolation and purification. Butyl alcohol also called biobutanolis now considered as a potential biofuel. In the early 20th century, butanol was used as a raw material for synthetic rubber production (Kaminski et al., 2011). It is a promising energy source of biological origin. Butanol is a primary straight-chain fuel with a molecular formula of $\mathrm{C}_{4} \mathrm{H}_{9} \mathrm{OH}$ including an alcohol functional group - $\mathrm{OH}$. It is non-hygroscopic, colourless, flammable alcohol. It is non-corrosive and possesses a higher calorific value. Production of butanol is made by a process called Acetone-butanol-Ethanol fermentation which is carried out mostly by bacteria Grampositive spore-forming bacteria known as Clostridium acetobutylicum. It is an anaerobic fermentation and is considered as one of the 
oldest methods for obtaining this solvent. It is believed that biobutanol production can decrease consumption of oil and natural gas by the automobile industry and reduce emissions of harmful gases into the environment.

\section{Need of biobutanol}

When compared with ethanol, it is found that butanol has properties like lower water solubility, less corrosive nature which makes its distribution through existing pipelines and distribution stations comparatively easy than ethanol. Compared to ethanol, blending is possible in higher concentrations without any vehicle retrofitting.

Thereby the share of renewable components in the final fuel mixture could be increased. Butanol has values closer to gasoline compared to ethanol like octane number, energy content, etc. making it a viable contender for biofuels.

It has better fuel economy $(\mathrm{Km} / \mathrm{L})$ is than with ethanol. Compared to ethanol, butanol has the lower heat of vaporisation which enables the easier starting of a motor in cold weather and also decreases the ignition problems.

It is safer to use and handle compared to ethanol as it has lower vapour pressure and higher flashpoint. In addition, it generates lower amounts of volatile organic compounds (VOC) emissions in internal combustion engines. Butanol is easily biodegradable in the environment and requires aerobic conditions to biodegrade.

It seems to be a potential alternative to petroleum due to high energy content, low volatility, less corrosive nature and lower affinity to moisture (Zhang et al., 2011; MohdAzhar et al., 2017). It has similar air-tofuel ratio and energy content as a result it can substitute gasoline without doing any alteration in the engine. Table 1 summarises the properties of butanol and other biofuels.

\section{Microorganisms involved in the production of biobutanol}

Clostridium acetobutylicum is a Grampositive, spore-forming. It is also known as Weizmann's organism as discovered by Claim Weizmann during World War I. It is the oldest microorganism used for $\mathrm{AB}$ fermentation process at the industrial scale. It utilizes sugars such as glucose, fructose, sucrose, lactose, mannose, starch and dextrins completely, while galactose, arabinose, xylose, raffinose, insulin, glycerol and mannitol are partially, but it does not ferment trehalose, rhamnose and melibiose not be fermented (Kumar and Gayen 2011, Lin et al., 2015). The most commonly used butanol-producing Clostridial strains are C. acetobutylicum, C. beijerinckii, C. saccharoperbutylacetonicum and $C$. saccharobutylicum. These strains do not havebutanol tolerance beyond concentrations of 13-20 g/l (varies species to species) (Garcia et al., 2011). Co-culturing of microorganisms is an emerging approach, which could perform more complicated tasks and endure more changeable environments than those of monocultures (Jiang et al., (2019). For enhanced butanol production, two anaerobic strains or one anaerobic and another aerobic strain are co-cultured. This also avoids strenuous anaerobic conditions. Co- culturing of anaerobic strain Clostridium butylicum TISTR 1032 with aerobic Bacillus subtilis WD161 led to a 6.5-fold increase in butanol production (7.4 g/l ABE) from cassava starch even without maintaining strenuous anaerobic conditions (Tran et al., 2010). Another promising approach is co-culturing of two anaerobic Clostridial strains where one strain produces intermediates of butanol fermentation that are further utilized by another strain to produce butanol. This will lead to efficient butanol production. Clostridium acetobutylicumis an amylolytic 
bacterium, hence considers starch as the preferred substrate for better production of butanol for. As we know, growth crops for the fermentation process are not very economical and will lead to the world food crisis. Hence one must look for such feed stocks which are not a part of food and are also very economical. Therefore, for butanol production, the most common feedstocks could be agricultural wastes, crop residues, etc. Other sources of plant biomassare microalgal cultures where production do not require a lot of work and costs (Dürre, 2008; Christi,2007; Christi 2008).

\section{Preprocessing of feedstocks}

Pretreatment of biomass is one of the most important upstream processes needed for better release of sugars which significantly improve the efficiency of fermentation. Different pretreatment techniques such as physical, chemical and physicochemical have been used by different researchers and selection of these techniques heavily depends on the characteristics and composition of feedstocks. The readily available firstgeneration feedstock and the presence of a high amount of sugar make that the most attractive raw material as there will be no requirement of complex pretreatment techniques. In the second-generation feedstocks, complex molecules like cellulose, hemicellulose and lignin are present which require complex pretreatment strategies for their removal and to ease the fermentation process. On the other hand, the thirdgeneration feedstock which is mainly the microalgae does not require any specific pretreatment, hence offers less complexity making it better source for biobutanol production.

\section{Production process}

In the course of the industrial output of biobutanol, using a fermentation process one must be considered factors like the evaluation of the process profitability, raw material cost and its pretreatment, a relatively small amount of product obtained, its significant toxicity, product recovery cost from fermentation broth. Though, the use of fermentation crop products is not very economical.

Therefore, agricultural wastes like straw, grass, leaves, fruits and spoiled grains etc. are used as these are more economical and profitable from fermentation point of view. After pretreatment of a substrate, it is inoculated with the microorganisms responsible for butanol production and fermentation starts. Three products- acetone, butanol and ethanol are produced in the ration of 3:6:1 along with some gases. The waste obtained must be pretreated before disposal.

\section{Methods of removal of butanol from the broth}

After the fermentation process, butanol must be recovered leaving behind the by-products formed. Efficient recovery of butanol from the fermentation broth omits its toxic effect on microbial cells. Distillation is a traditional method of product recovery. Currently, other methods are being used such as adsorption, pervaporation membrane protraction, gas stripping. Particularly, pervaporation is considered as a potentially promising way to recover butanol from fermentation broth due to single process separation and concentration of the product obtained.

\section{Challenges in commercial biobutanol production}

Nevertheless, the commercial-scale biobutanol production is proliferating, industries are still facing a number of hurdles that need to surmount for economical production.

Notably, the development of butanol tolerant strain, overall cost reduction, sluggish 
fermentation, lower yield, uneconomical product recovery and separation of microorganisms are the main challenges that need to be resolved. Algae-based biobutanol production is still under developmental stages. Lower concentration and end product toxicity could be addressed by using the metabolic engineering techniques and the co-culturing methods for maximum utilization of rawbiomass, integrated production and recovery systems to minimize the toxicity level.

The application of different nanomaterials for the processing of biomass is an important aspect. Still, research is needed to explore its uses during fermentation to enhance productivity and to improve the challenges associated with it. There is a need for the development of more versatile nanocatalysts for a range of biomass.

Nanoparticles that can be used as biocatalysts to convert extracted sugars to biobutanol must be synthesised, Along with that their commercialization is necessary to increase the biomass processing and production efficiency at the industrial scale.

Biobutanol can be obtained more efficiently by using biochemical methods as chemical synthesis is not very economical. The major problem that arises in the application of biochemical methods is the end product toxicity and low butanol concentration. To resolve this problem, metabolic engineering could of a promising approach for biobutanol production.

Biobutanol has a positive impact on ecology. It can be used as a fuel additive as it is proved to be a better fuel component than other alcohols due to close resemblance to gasoline. Its application would result in reductions of greenhouse gas emissions. Also, the application of nanocatalysts could reduce the cost of production and may improve productivity, but their applications on commercial-scale still need to be explored

Table.1 Properties of butanol and other biofuels (Ha et al., 2010)

\begin{tabular}{|c|c|c|c|c|}
\hline Fuel & $\begin{array}{c}\text { Combustion energy } \\
{\left[\mathbf{M J} / \mathbf{d m}^{\mathbf{3}}\right]}\end{array}$ & $\begin{array}{c}\text { Heat of } \\
\text { Evaporation } \\
{[\mathbf{M J} / \mathbf{k g}]}\end{array}$ & $\begin{array}{c}\text { Research Octane } \\
\text { Number }\end{array}$ & $\begin{array}{c}\text { Motor octane } \\
\text { Number }\end{array}$ \\
\hline Petrol & 32 & 0.36 & $91-99$ & $81-89$ \\
\hline Butanol & 29.2 & 0.43 & 96 & 78 \\
\hline Ethanol & 19.6 & 0.92 & 130 & 96 \\
\hline Methanol & 16 & 1.2 & 136 & 104 \\
\hline
\end{tabular}

\section{References}

Christi Y. Biodiesel from microalgae beats bioethanol. Trends Biotechnol., 2008; 26(3):. 126-131.

Christi Y. Biodiesel from microalgae. Biotechnol. Advan., 2007; 25: 294306.

Dürre P. Fermentative butanol production bulk chemical and biofuel. Ann. N. Y. Acad. Sci., 2008; 1125: 353-362
Garcia V, Pakkila J, Ojamo H, Muurinen E, Keiski RL. Challenges in biobutanol production: how to improve the efficiency. Renew Sust Energy Rev, 2011; 15: 964-980.

Ha S.H., Ngoc Mai N.L. and Koo Y.M.: Butanol recovery from aqueous solution into ionic liquids by liquidliquid extraction, Process Biochem., 2010, 45: 1899-1903.

Jiang Y, Wu R, Jie Zhou, He A, Xu J, Xin F, 
Zhang W, Ma J, Jiang M and Dong W. Recent advances of bifuels and biochemicals production from sustainable resources using cocultivation systems. Biotechnology for Biofuels, 2019, 12:155.

Kamiński, W., Tomczak, E. and Górak, A.Biobutanol - Production and Purification Methods. Ecological Chemistry and Engineering S, 2011, 18(1).

Kumar M, Gayen K. Developments in biobutanol production: new insights. Appl Energy, 2011; 88: 1999-2012.

Lin DS, Yen HW, Kao WC, Cheng CL, Chen WM, Huang CC, Chang JS. Biobutanol production from glycerol with Clostridium pasteurianum $\mathrm{CH} 4$ : the effects of butyrate addition and in situ butanol removal via membrane distillation. Biotechnol Biofuels, 2015; 8: 168.
MohdAzhar, S.H., Abdulla, R., Jambo, S.A., Marbawi, H., Gansau, J.A., MohdFaik, A.A. \& Rodrigues, K.F. Yeasts in sustainable bioethanol production: a review. Biochemistry and Biophysics Reports, 2017, 10, 52-61.

Tran HTM, Cheirsilp B, Hodgson B, Umsakul K. Potential use of Bacillus subtilis in a co-culture with Clostridium butylicum for acetone-butanol-ethanol production from cassava starch. Biochem. Eng. J, 2010; 48: 260-267.

Zhang, L., Zhao, H., Gan, M., Jin, Y., Gao, X., Chen, Q., Guan, J. and Wang, Z. Application of simultaneous saccharification and fermentation (SSF) from viscosity reducing of raw sweet potato for bioethanol production at laboratory, pilot and industrial scales. Bioresource Technology, 2011, 102 (6), 4573-4579.

\section{How to cite this article:}

Sonam Antil. 2019. Biobutanol: Production, Scope and Challenges. Int.J.Curr.Microbiol.App.Sci. 8(11): 580-584. doi: https://doi.org/10.20546/ijcmas.2019.811.070 